\title{
Iniciadores de turno em função da polidez
}

\author{
Alzira V. Tavares de Macedo \\ Universidade Federal do Rio de Janeiro
}

\section{Abstract}

This paper examines the use of discourse markers as turn takers and shows how they are correlated to politeness factors.

More than 7000 beginnings of turns are analyzed in interviews with speakers from Rio de Janeiro using the methodology of language variation proposed by Labov. Factors such as type of discourse, complexity and change of topic in the interview, argumentative attitude of the interviewee, etc. are seen as face threatening contexts that require polite strategies such as the use of discourse markers.

The functionalist approach of the paper is discussed, as long as structural items are interpreted as motivated by the context of interaction. 


\section{INTRODUÇÃO}

S inícios de turno são locais importantes na conversa, nos
quais os falantes lutam para pegar a palavra e, quando
conseguem a vez de falar, vêem-se diante de uma situação delicada: devem, ao mesmo tempo, manter a coesão do que está sendo dito, a atenção dos presentes, bem como a harmonia na interação. Em vez de ir direto ao assunto, "preparam o espírito" de seus interlocutores antes de atacar. Tais situações interacionais deixam reflexos na estrutura lingüística, entre elas, os marcadores.

Neste trabalho, procuro mostrar que a presença de "marcas lingüísticas" na posição de início de turno, especialmente aquelas que vêm sendo chamadas de "marcadores conversacionais", pode ser explicada pelas teorias de polidez.

Uso o termo no sentido de Schiffrin (1986), Marcuschi (1986), Castilho (1983), Roulet et alii (1985), Silva \& Macedo (1989; 1992), ou ainda Vincent (1993), para as diversas categorias gramaticais como advérbios (bem, agora, assim, aí), interjeições (ah, oh, pô, poxa, ai meu Deus), conjunções (mas, então, aí, e, porque), ou mesmo orações (eu acho, acho que sim, acho que não, quer dizer) usadas, no discurso, fora das funções previstas nas gramáticas tradicionais, geralmente com perda de conteúdo semântico.

As teorias de polidez prevêem que as situações mais "custosas", onde a interação se torne mais delicada, tendem a utilizar estratégias de polidez (Brown \& Levinson, 1982 e 1987; Tannen, 1985; Macedo \& Brito, 1985; Rosa, 1992) como um modo de proteger a face dos participantes. Considero as partículas ou expressões iniciadoras de turno, ilustradas nos exemplos abaixo, como marcas de polidez. Como constituem material fônico "extra", defendo aqui que sua principal função é a de quebrar a assertividade da resposta. Procuro então mostrar que tais marcas são usadas justamente nos ambientes 
mais custosos ou "ameaçadores", confirmando as hipóteses das teorias de polidez.

O inventário completo dos "marcadores", bem como os locais exatos em que esses podem ocorrer, estão sendo gradativamente descritos pelos estudiosos do discurso na última década. Mesmo assim, não se sabe com precisão onde cada item teria que ocorrer, para que se possa realizar um estudo ortodoxo de variação que compare presença ou ausência de marcador no interior do discurso. Ao fixar-se a posição de início de turno, no entanto, isso se torna possível, sendo essa uma sugestão metodológica para os que desejam realizar análises quantitativas com marcadores.

Tal tipo de abordagem pode ser considerada como funcionalista do tipo givoniano, na medida em que o emprego e, em última análise, a gramaticalização de uma "categoria"de itens são explicados como função de motivações discursivo-interacionais (Givon, 1979; Nichols, 1984).

Nos exemplos de (1) a (16) abaixo, as partículas em itálico ilustram o que estou chamando de "iniciadores" de turno:

1) E: E quando tiver água você acha que vai melhorar?

F: Ai melhora demais, porque a gente com água dentro de casa é outra coisa. (060278)

2) E: Vem cá, se você fosse presidente da república, imagina o que você ia fazer para este povo.

F: Ai meu Deus. Espera aí, meu Deus. Nem pensava. Ia nessas favelas mais ruinzinhas que têm e ajudava o pessoal. (061052)

3) E: Mas então, ela terminou com o Gil?

F: Acho que terminou sim. E ele ficou muito chateado. (101702).

4) E: E você vota?

F: $A h$, voto! Na maior alegria, na maior empolgação. (441077)

5) E: Mas foi bom ter dez crianças em casa?

F: Bom, era não é? Por que eu sempre gostei muito. (180613)

6) E: Mas esses seus amigos que o senhor disse que também estão entrando para ser vereador agora, não é? O senhor acha então que eles, por exemplo, são honestos, assim? 
F: Ih, isso é uma mentira. Não existe honesto nessa terra.

7) E: Mas o senhor está falando em equipe não é?

F: Pois é. Não, mas ainda não.

8) E: Tem que alertar?

F: Tem que alertar. Agora minha m_e já é diferente, não é?

9) E: Sobre moda, você se interessa?

F: Oh, moda! Eu gosto. Eu faço minha moda, tudo que estiver usando, eu faço o possível para ter. (231437)

10) E: Família mesmo, não é.

F: Então, eu, como fui sempre criado com família, nesse ambiente de família, nesse negócio... (311472)

11) F: ...mulher também não tem nada que ficar prendendo homem. (...) Não tem nada que prender. Sabe se ele vai atrás de mulher para apanhar um dinheiro com outra mulher para trazer para dentro de casa? Também não sabe, não e?

E: Pois é.

F: Então o homem tem que estar sempre na rua. É procurando, fazendo um biscate, isso, aquilo outro, (...)

12) E: Ah, sempre trabalhou em casa.

F: Hum, apanhava e fazia em casa. Costura. Agora, da roupa, limpeza assim era fora, não é... (351977)

13) E: Ele falou que queria tainha. Tainha é bom?

F: É. Mas não é o melhor. (030315)

14) E: Depois vamos dar uma voltinha lá?

F: É. Depois vai até lá porque é bonito lá. (030982)

15) E: Ah, você não gosta de ter amigos, assim?

F: Mas nem todos s_o amigos. Ele chama pra mim atender. (031352)

16) E: Não?

F: Porque passa rápido, você sambando passa rápido... (25 0386) 


\section{METODOLOGIA}

\subsection{Emprego de marcas em geral}

$\mathrm{Na}$ primeira parte do trabalho, levei em conta todas as partículas ou expressões (interjeição, conjunção, advérbio ou expressões típicas da fala), ocorridas na primeira posição. Foram também levantados os inícios de respostas que repetiam o final da pergunta antecedente, que chamei de "repetições", bem como as respostas sem qualquer marca, que chamei de "zero".

Os seguintes "iniciadores de turnos" foram encontrados nessa primeira amostragem, com base em 30 entrevistas da "Amostra Censo", ${ }^{1}$ com falantes adultos da cidade do Rio de Janeiro (Silva \& Scherre, 1996): ${ }^{2}$

Tabela 1 - Tipos de iniciadores

\begin{tabular}{|l|r|r|}
\hline Zero & 2444 & $54,75 \%$ \\
\hline Não & 659 & $14,76 \%$ \\
\hline Ah & 519 & $11,63 \%$ \\
\hline Repetição & 170 & $2,81 \%$ \\
\hline É & 120 & $2,69 \%$ \\
\hline Pergunta & 109 & $2,44 \%$ \\
\hline Eu acho & 71 & $1,59 \%$ \\
\hline Olha & 68 & $1,52 \%$ \\
\hline Bom & 42 & $0,94 \%$ \\
\hline Porque & 35 & $0,78 \%$ \\
\hline Aí & 32 & $0,72 \%$ \\
\hline Mas & 30 & $0,67 \%$ \\
\hline Pois é & 28 & $0,63 \%$ \\
\hline Acho que & 26 & $0,58 \%$ \\
\hline sim/não & & \\
\hline
\end{tabular}

\begin{tabular}{|l|c|c|}
\hline Ih & 19 & $0,42 \%$ \\
\hline Então & 18 & $0,40 \%$ \\
\hline Que & 16 & $0,36 \%$ \\
\hline Ai/ai meu Deus & 11 & $0,25 \%$ \\
\hline Hum & 9 & $0,20 \%$ \\
\hline É isso aí, & & \\
\hline É isso mesmo & 9 & $0,18 \%$ \\
\hline Oh & 8 & $0,18 \%$ \\
\hline Quer dizer & 5 & $0,11 \%$ \\
\hline Eu sei lá & 4 & $0,09 \%$ \\
\hline E & 4 & $0,09 \%$ \\
\hline Poxa / pô & 4 & $0,09 \%$ \\
\hline Que & 2 & $0,04 \%$ \\
\hline Bem & 2 & $0,04 \%$ \\
\hline Assim & 1 & $0,02 \%$ \\
\hline
\end{tabular}


Embora a maioria das respostas ocorra sem qualquer preparação, ou seja, sem iniciadores, é expressivo o fato de que em quase a metade dos casos ocorreu alguma marca no início do turno (Tab. 2):

Tabela 2 - Presença $x$ ausência de alguma marca

\begin{tabular}{|l|l|l|}
\hline Com algum iniciador & $2032 / 4476$ & $45,37 \%$ \\
\hline Sem iniciador & $2444 / 4476$ & $54,63 \%$ \\
\hline
\end{tabular}

Comparei em bloco a presença versus ausência de alguma marca, atendo-me apenas à primeira partícula ou expressão de cada turno de resposta. ${ }^{3}$ Nas entrevistas, considerei como "contextos" que poderiam constituir situações delicadas ou custosas, tratando-os como grupos de fatores, quatro tipos de situações: a) o tipo de estrutura da pergunta (perguntas cujas respostas afirmativas ou negativas estão centradas no verbo, perguntas com pronomes interrogativos, perguntas com "você acha" ou que pedem a opinião do entrevistado, seqüência de perguntas, perguntas no imperativo ou em forma afirmativa, marcadores ou estímulos (back channels) usados pelo entrevistador); b) a seqüência do assunto na entrevista (com ou sem mudança de assunto em relação ao que vinha sendo tratado); c) o grau de complexidade do assunto (assunto geral, pessoal, complexo e sem conteúdo), sendo considerados "assuntos complexos" aqueles de conteúdo difícil, como, por exemplo, falar sobre diferenças fonéticas entre os sotaques regionais, falar sobre física nuclear, etc. e d) a concordância ou não do interlocutor em relação à pergunta do entrevistador (concorda, discorda, enumera, continua resposta anterior).

Vejamos exemplos dos fatores acima estudados:

\section{a) Estrutura sintática da pergunta}

Perguntas de resposta afirmativa ou negativa

17) E: Mas ela pode tomar conta dos netos?

F: Pode. Ah dos netos, ela fica com os netos. (040035) 
Perguntas com pronomes interrogativos

18) E: Que é que você gosta de fazer?

F: Ah! Gosto de fazer tudo... (040408)

Perguntas com "você acha" ou pedindo opinião

19) E: E você acha que lá eles falam melhor do que aqui?

F: Ah! Eu não sei, porque eu não tinha muito contato. (041045)

Perguntas com repetição trecho antecedente

20) E: Eles falam palavrão?

F: Palavrão? Eu acho que às vezes (...).

Seqüência de perguntas

21) E: Seu pai tem estudo também? Ele foi à escola?

F: Meu pai foi à escola. Agora até que série estudou, não sei. (040671)

Perguntas com imperativo/ forma afirmativa

22) E: Me conta como é que foi?

F: Acho que foi (...).

Perguntas do tipo backchannel

23) E: Que coisa boa.

F: É isso...

Perguntas sem verbo/elipse do verbo

24) E: Por quê?

F: Ah. Tudo que eu estou sentindo que eu quero fazer, eu falo com ela. (040074)

\section{b) Seqüência do assunto}

Muda assunto

25) E: Mudando um pouco de assunto, você falou...C. Grande.

F: Campo Grande. (050593)

Não muda assunto (a pergunta segue-se ao exemplo acima)

26) E: Campo Grande já é cidade?

F: Não é aquela cidade assim, sabe? mas progrediu muito, sabe? (050597) 
Insiste (em relação ao exemplo acima)

27) E: Mas não é considerado bairro do Rio, não?

F: É um bairro, é um bairro sim (...)

E: As pessoas que moram lá vêem C. Grande como bairro ou como cidade?

F: As pessoas...acho que... (050633)

\section{c) Complexidade do assunto}

Assunto complexo ou embaraçoso

28) E: E que tipo de palavras são essas?

F: Ah! Às vezes o mais velho chega com coisas do colégio, falando palavrão.

E: Pode falar palavrão. Não tem problema, não.

F: Onde você aprendeu? Ah, mamãe, foi no colégio...

E: E qual é o tipo de palavrão?

F: Ah! Ele fala merda... (040720)

Assunto pessoal

29) E: Que idade você tinha, quando eles se separaram?

F: Ah! Eu deveria ter uns 9. (040323)

Assunto geral/informativo

30) E: Aqui dá muita briga?

F: Aqui?Aonde? Ali onde eu moro?

E: É.

F: Ah! Dá. (040372)

Sem conteúdo (perguntas constituídas por marcadores ou backchannels)

31) E: Certo.

F: Que ele estava foi pelo quartel, então ele tinha que ficar lá. (041040) 


\section{d) Concordância da resposta}

Concorda com a expectativa da pergunta

32) E: Mas ela pode tomar conta dos netos?

F: Pode. Ah dos netos, ela fica com os netos. Ela não esquenta.

$\mathrm{E}$ : E os netos gosta?

F: Gosta dela demais. Quando ela sai... (040041)

Não concorda

33) E: Mas difícil, assim, por quê?

F: Não sei.

E: É porque é a língua deles, não é?

F: Não sei. (041084)

Como "enumeração", "continuação resposta anterior" ou "outros", incluí os casos em que não se aplicava a questão da concordância ou discordância em relação à pergunta.

$\mathrm{Na}$ entrevista do tipo laboviano que constitui a Amostra Censo, grande parte das perguntas é feita com o verbo (pergunta que exige resposta sim/não). Os tipos de discurso informativo e argumentativo são os mais comuns nas respostas. A continuação do assunto é o mais comum, já que, na entrevista, "uma coisa puxa a outra", fazendo fluir o assunto com poucas mudanças bruscas. A maioria das respostas do entrevistado concorda com a pergunta, pelo menos no início de seu desenvolvimento. Pude observar, de maneira ainda assistemática, que o entrevistador é quem fica pouco à vontade e parece fazer maior uso de iniciadores do que o entrevistado. Para o presente trabalho, o objetivo foi o de estudar os falantes da Amostra, mas já está em andamento uma outra etapa da pesquisa sobre as perguntas dos entrevistadores.

Voltemos então ao tema central desta primeira parte, que é o uso de alguma marca no início das respostas, correlacionado aos quatro contextos interativos mencionados. ${ }^{4}$ 
Tabela 3 - Uso de iniciadores quanto d̀ estrutura da pergunta

\begin{tabular}{|l|r|c|}
\hline Pergunta sim/não & $432 / 1580$ & $27,54 \%$ \\
\hline Pronomes interrogativos & $339 / 755$ & $44,90 \%$ \\
\hline Você acha/opinião & $155 / 322$ & $48,14 \%$ \\
\hline Repetição & $22 / 7$ & $28,57 \%$ \\
\hline Seqüência de perguntas & $17 / 61$ & $27,87 \%$ \\
\hline Imperativo ou forma afirm. & $299 / 876$ & $44,87 \%$ \\
\hline Marcadores/backchannel & $74 / 244$ & $30,33 \%$ \\
\hline Sem verbo & $37 / 104$ & $35,58 \%$ \\
\hline
\end{tabular}

Tabela 4 - Uso de iniciador e seqüência do assunto

\begin{tabular}{|l|r|c|}
\hline Muda assunto & $192 / 470$ & $40,85 \%$ \\
\hline Não muda & $1110 / 3226$ & $34,41 \%$ \\
\hline Insiste & $73 / 123$ & $59,35 \%$ \\
\hline
\end{tabular}

Tabela 5 - Uso de iniciador e concordância da resposta

\begin{tabular}{|l|c|c|}
\hline Concorda com a expectativa da pergunta & $1079 / 2686$ & $40,17 \%$ \\
\hline Não concorda & $194 / 221$ & $87,88 \%$ \\
\hline Enumera, continua ou outros & $202 / 912$ & $22,15 \%$ \\
\hline
\end{tabular}

Tabela 6 - Uso de iniciadores por complexidade do assunto

\begin{tabular}{|l|c|c|}
\hline Assunto complexo & $188 / 395$ & $47,59 \%$ \\
\hline Assunto pessoal & $42 / 1042$ & $39,16 \%$ \\
\hline Assunto geral & $729 / 2182$ & $33,41 \%$ \\
\hline
\end{tabular}

Como se vê na Tabela 3, as perguntas com pronomes interrogativos e as perguntas de opinião ocorreram com o maior número de iniciadores. Ora, essas perguntas são justamente as que vão exigir um desenvolvimento maior das respostas, especialmente as argumentivas, situações mais custosas porque expõem a "face" do falante, conforme as hipóteses da polidez. 
Na Tabela 4, as situações de insistência, ou mesmo a mudança de assunto em relação ao que vinha sendo abordado por parte dos entrevistadores, apresentam também mais iniciadores, talvez porque exijam mais cuidado nas respostas, que se tornam mais elaboradas ou "defensivas".

Já na Tabela 5, os assuntos complexos e de ordem pessoal são os que produzem respostas com mais iniciadores, pois, ao que tudo indica, são mais "custosos" para o falante.

Finalmente, na Tabela 6, as respostas em que o falante revela discordância em relação às expectativas da pergunta podem ser interpretadas como "ameaçadoras à face" e, de fato, apresentam um maior emprego de marcas no início do turno.

Comparamos o emprego das marcas entre homens e mulheres (Tabela 7), na hipótese de que as mulheres usariam mais iniciadores, já que o estudo específico de alguns marcadores havia revelado diferenças entre os sexos (Silva \& Macedo, 1996). No entanto, tal expectativa não se confirmou, possivelmente porque, ao reunirmos em bloco todos os iniciadores, acabamos neutralizando funções diversificadas e especializadas que cada um parece ter.

Tabela 7 - Uso de iniciadores por sexo

\begin{tabular}{|l|l|l|l|l|}
\hline & \multicolumn{2}{|c|}{ Mulheres } & \multicolumn{2}{c|}{ Homens } \\
\hline Com iniciadores & $433 / 1411$ & $30,69 \%$ & $162 / 568$ & $28,52 \%$ \\
\hline Sem iniciadores & $968 / 1411$ & $68,31 \%$ & $406 / 568$ & $71,48 \%$ \\
\hline
\end{tabular}

\subsection{Análise dos marcadores conversacionais em início de turno}

Para esta segunda etapa, utilizei como amostra entrevistas com 18 falantes adultos e 12 falantes crianças. A inclusão dos dados de crianças foi importante porque permitiu mostrar o processo de aquisição dessas estratégias discursivas. Os iniciadores de turno da lista apresentada foram então englobados em 4 tipos, para que 
pudessem ser quantificados com a utilização do programa de regras variáveis:

a) Marcadores (forma inequivocamente em sua função discursiva, já com perda de sua função sintática enquanto conjunção, advérbio, adjetivo ou expressão).

b) Conectivos (itens como conjunções e advérbios, ainda em flutuação, ora em funções sintáticas, ora funções discursivas já um tanto esvaziados de seu conteúdo. Na dúvida, foram separados).

c) Zero

d) Repetição do trecho antecedente

Os dados assim recodificados, nessa segunda etapa, puderam então ser passados no programa computacional VARBRUL 2S eneário (Pintzuk, 1988). Tomaram-se os quatro tipos acima como variáveis dependentes, correlacionando-os a grupos de fatores sociais (sexo, idade e escolaridade) e discursivo-interacionais bem aproximados aos já descritos acima (estrutura da pergunta e tipo de discurso das perguntas, seqüência do assunto no discurso, grau de complexidade das perguntas e tipo de discurso das respostas).

Os resultados, nas tabelas abaixo, devem ser lidos com a atenção voltada para os índices em negrito da coluna dos "marcadores", a ser comparada com a coluna de dados sem qualquer marca, ou "zero".

Quanto ao fator sexo (Tabela 8), agora estudado de modo mais específico, destacando os "marcadores discursivos" das demais marcas em início de turno, observamos nitidamente a maior utilização de marcadores por parte das mulheres do que pelos homens. Estas usam mais marcadores e conectivos, enquanto os homens usam mais zeros e repetições: 
Tabela 8 - Iniciadores por sexo

\begin{tabular}{|l|cc|cc|cc|cc|}
\hline \multirow{2}{*}{ Sexo } & \multicolumn{2}{|c|}{ Marcador } & \multicolumn{2}{c|}{ Conectivo } & \multicolumn{2}{c|}{ Zero } & \multicolumn{2}{c|}{ Repetição } \\
\cline { 2 - 8 } & apls. freq. p.rel. & apls. freq. p.rel. & apls. & freq. & p.rel. & apls. & freq. & p.rel. \\
\hline Mulher & $984 / 4268=23 \%$ & $\mathbf{3 2}$ & $1083 / 4268=25 \%$ & .27 & $2008 / 4268=47 \%$ & .22 & $2008 / 4268=47 \%$ & .22 \\
\hline Homem & $352 / 2777=23 \%$ &. $\mathbf{1 9}$ & $563 / 2777=20 \%$ & .23 & $1680 / 2777=60 \%$ & .28 & $182 / 2777=77 \%$ & .30 \\
\hline
\end{tabular}

Quanto à idade a hipótese levantada foi a de que deveria haver diferenças, como havia sido observado em trabalhos anteriores (Macedo, 1997a;1997b), já que os marcadores exercem funções discursivas que, em crianças, seriam adquiridas bem mais tarde. Os adultos teriam um discurso bem mais fluente e adequado socialmente do que as crianças, principalmente no que diz respeito às normas de polidez. Entretanto se observarmos a Tabela 2, veremos que seus resultados só corroborariam a hipótese para o caso das crianças de 4 a 6 anos, já que o grupo de de 8 a 10 anos apresentou índices mais altos do que o dos adolescentes e adultos:

\section{Tabela 9 - Iniciadores por faixa etária}

\begin{tabular}{|l|cc|cc|cc|cr|}
\hline & \multicolumn{2}{|c|}{ Marcador } & \multicolumn{2}{c|}{ Conectivo } & \multicolumn{2}{c|}{ Zero } & \multicolumn{2}{c|}{ Repetição } \\
\hline Idade & apls. freq. p.rel. & apls. freq. p.rel. & apls. freq. p.rel. & apls. freq. & p.rel. \\
\hline $4-6$ & $73 / 1045=7 \%$ & .13 & $224 / 1045=21 \%$ & .14 & $706 / 1045=47 \%$ & $\mathbf{. 5 2}$ & $42 / 1045=4 \%$ & .20 \\
\hline $8-10$ & $370 / 1562=24 \%$ &. $\mathbf{3 4}$ & $445 / 1562=28 \%$ & .35 & $700 / 1562=60 \%$ & .16 & $47 / 1562=3 \%$ & .15 \\
\hline $15-24$ & $232 / 1534=15 \%$ & .24 & $298 / 1534=19 \%$ & .25 & $917 / 1534=60 \%$ & .22 & $87 / 1534=6 \%$ & .29 \\
\hline+ de 25 & $661 / 2904=23 \%$ &. $\mathbf{2 6}$ & $679 / 2904=23 \%$ & .23 & $1365 / 2904=47 \%$ & .16 & $199 / 2904=7 \%$ & .33 \\
\hline
\end{tabular}

Tal resultado, inesperado, poderia dever-se à má distribuição dos grupos de fatores idade e escolaridade (todas as crianças menores estão no grupo considerado como "sem escola" (jardim de infância, pré-primário, etc.)). Assim, novos cálculos foram feitos, retirando-se o grupo de fatores "escolaridade", obtendo-se, todavia, a mesma gradação inexplicável (Tabela 10), de que a faixa etária de 8 a 10 anos seria importante para a aquisição dessas estratégias. 


\section{Tabela 10 - Iniciadores por faixa etária (retirado o grupo escolaridade)}

\begin{tabular}{|l|cc|cc|cc|cc|}
\hline & \multicolumn{2}{|c|}{ Marcador } & \multicolumn{2}{c|}{ Conectivo } & \multicolumn{2}{c|}{ Zero } & \multicolumn{2}{c|}{ Repetição } \\
\hline Idade & apls. freq. p.rel. & apls. freq. p.rel. & apls. & freq. & p.rel. & apls. freq. & p.rel. \\
\hline $4-6$ & $73 / 1045=7 \%$ & .14 & $224 / 1045=21 \%$ & .28 & $706 / 4045=68 \%$ & .35 & $42 / 1045=4 \%$ & .23 \\
\hline $8-10$ & $370 / 1562=24 \%$ &. $\mathbf{3 4}$ & $445 / 1562=28 \%$ & .31 & $700 / 1562=45 \%$ & .19 & $47 / 1562=3 \%$ & .16 \\
\hline $15-24$ & $232 / 1534=15 \%$ & .24 & $298 / 1534=19 \%$ & .20 & $917 / 1534=60 \%$ & .27 & $87 / 1534=6 \%$ & .29 \\
\hline+ de 25 & $661 / 2904=23 \%$ & .28 & $679 / 2904=23 \%$ & .19 & $1365 / 2904=47 \%$ & .19 & $199 / 2904=7 \%$ & .33 \\
\hline
\end{tabular}

Observemos agora, na Tabela 11, os resultados quanto ao nível de escolaridade do falante.

\section{Tabela 11 - Iniciadores por escolaridade}

\begin{tabular}{|l|cc|cc|cc|cc|}
\hline & \multicolumn{2}{|c|}{ Marcador } & \multicolumn{2}{c|}{ Conectivo } & \multicolumn{2}{c|}{ Zero } & \multicolumn{2}{c|}{ Repetição } \\
\hline Nível & apls. freq. p.rel. & apls. freq. p.rel. & apls. freq. p.rel. & apls. freq. & p.rel. \\
\hline s/escola & $73 / 1044=7 \%$ &. $\mathbf{2 8}$ & $224 / 1044=21 \%$ & .39 & $705 / 1044=68 \%$ & .15 & $42 / 1044=4 \%$ & .24 \\
\hline $1^{\circ}$ grau & $839 / 3868=22 \%$ & .24 & $993 / 3868=26 \%$ & .21 & $1839 / 3868=48 \%$ & .31 & $197 / 3868=5 \%$ & .24 \\
\hline $2^{\circ}$ grau & $424 / 2133=20 \%$ & .26 & $429 / 2133=20 \%$ & .18 & $1144 / 2133=54 \%$ & .32 & $136 / 2133=6 \%$ & .24 \\
\hline
\end{tabular}

Na coluna dos marcadores, o grupo de crianças sem escola exibiu um peso relativo ligeiramente mais alto do que os grupos no primeiro e segundo graus.

Após essa testagem detalhada, minha interpretação seria a de que a escolaridade, tal como a idade, também não estaria consistentemente correlacionada ao emprego dos marcadores discursivos iniciadores. Mais uma vez, porém, levando-se em conta que não houve independência total entre idade e escolaridade, foi feita a quantificação dos dados, desta feita retirando-se o grupo idade, com os seguintes resultados (Tabela 12): 


\section{Tabela 12 - Iniciadores por escolaridade (retirado o grupo de fator idade)}

\begin{tabular}{|c|c|c|c|c|}
\hline & Marcador & Conectivo & Zero & Repetição \\
\hline Nível & apls. freq. p.rel. & apls. freq. p.rel. & apls. freq. p.rel. & apls. freq. p.rel. \\
\hline s/escola & $73 / 1044=7 \% \quad . \mathbf{. 1 5}$ & $224 / 1044=21 \% .28$ & $705 / 1044=68 \% \quad .34$ & $42 / 1044=4 \% \quad .23$ \\
\hline $1^{\circ}$ grau & $839 / 3868=22 \% \quad .32$ & $993 / 3868=26 \% .26$ & $1839 / 3868=48 \% \quad . \mathbf{1 9}$ & $197 / 3868=5 \% \quad .23$ \\
\hline $2^{\circ}$ grau & $424 / 2133=20 \% \quad . \mathbf{3 1}$ & $429 / 2133=20 \% .20$ & $1144 / 2133=54 \% \quad .22$ & $136 / 2133=6 \% \quad .27$ \\
\hline
\end{tabular}

Os resultados da Tabela 12 estão mais de acordo com a hipótese, indicando que os falantes sem escola usam bem menos marcadores do que os falantes com escola em geral (primeiro e segundo graus).

Voltemo-nos agora para os grupos de fatores discursivointeracionais.

Tal como na primeira parte do trabalho, no cálculo com as variáveis múltiplas também considerei, de um lado a estrutura sintática da pergunta, e, de outro, o seu conteúdo mais argumentativo ou mais informativo. A maioria das perguntas com pronomes interrogativos acabou por propiciar respostas mais longas e mais argumentativas, sendo esta a classificação mais adequada, que chamamos de "tipo de discurso da resposta", conforme a Tabela 13:

Tabela 13 - Iniciadores de turno por tipo de discurso das respostas

\begin{tabular}{|c|c|c|c|c|}
\hline & Marcador & Conectivo & Zero & Repetição \\
\hline Tipo & apls. freq. p.rel. & apls. freq. p.rel. & apls. freq. p.rel. & apls. freq. p.rel. \\
\hline Argum. & $336 / 1260=27 \% \quad \mathbf{3 1}$ & $295 / 1260=23 \% .27$ & $570 / 1260=45 \% . \mathbf{. 2 3}$ & $59 / 1260=5 \% \quad .20$ \\
\hline Informat. & $839 / 3868=22 \% \quad . \mathbf{2 0}$ & $1351 / 5785=26 \% .23$ & $3118 / 5785=48 \% \quad .27$ & $316 / 5785=5 \% \quad .31$ \\
\hline
\end{tabular}

Vejamos agora, na Tabela 14, os resultados obtidos para os tipos de pergunta: 


\section{Tabela 14 - Iniciadores por tipo de pergunta}

\begin{tabular}{|l|r|r|rrr|rr|}
\hline \multirow{2}{*}{ tipos } & \multicolumn{2}{|c|}{ Marcadores } & \multicolumn{2}{|c|}{ Conjunções } & \multicolumn{2}{|c|}{ Zero } & \multicolumn{2}{c|}{ Repetição } \\
\cline { 2 - 7 } & apls. freq. p.rel. & apls. freq. p.rel. & apls. freq. p.rel. & apls. freq. & p.rel. \\
\hline $\begin{array}{l}\text { ped. de } \\
\text { opinião }\end{array}$ & $196 / 606=32 \% . \mathbf{3 0}$ & $98 / 606=16 \% .21$ & $269 / 606=44 \%$ & $\mathbf{. 2 1}$ & $43 / 606=7 \%$ & .29 \\
\hline $\begin{array}{l}\text { Backchan. } \\
\text { Backais } \\
\text { casos }\end{array}$ & $1048 / 5936=20 \% .23$ & $1402 / 5936=20 \% .26$ & $3179 / 5936=54 \%$ &. $\mathbf{2 9}$ & $307 / 5936=5 \%$ & .22 \\
\hline
\end{tabular}

Na Tabela 15 podemos observar os resultados relacionados à seqüência do assunto:

\section{Tabela 15 - Iniciadores de acordo com a seqüência do assunto}

\begin{tabular}{|l|c|c|c|cc|cc|}
\hline \multirow{2}{*}{$\begin{array}{l}\text { seqüência } \\
\text { do assunto }\end{array}$} & Marcadores & \multicolumn{2}{|c|}{ Conjunções } & \multicolumn{2}{c|}{ Zero } & \multicolumn{2}{c|}{ Repetição } \\
\cline { 2 - 8 } & apls. freq. p.rel. & apls. freq. p.rel. & apls. freq. p.rel. & apls. freq. & p.rel. \\
\hline $\begin{array}{l}\text { insiste no } \\
\text { assunto }\end{array}$ & $89 / 270=33 \% .35$ & $55 / 270=20 \%$ & .24 & $113 / 270=42 \%$ &. $\mathbf{2 0}$ & $13 / 270=5 \%$ & .22 \\
\hline $\begin{array}{l}\text { muda de } \\
\text { assunto }\end{array}$ & $230 / 1236=19 \% .21$ & $251 / 1236=20 \%$ & .23 & $687 / 1236=56 \%$ & .28 & $68 / 1236=6 \%$ & .28 \\
\hline $\begin{array}{l}\text { não muda } \\
\text { de assunto }\end{array}$ & $1017 / 5539=18 \% .21$ & $1340 / 5539=24 \% .28$ & $2888 / 5539=52 \%$ & .27 & $294 / 5539=5 \%$ & .25 \\
\hline
\end{tabular}

Quanto ao tipo de assunto, os resultados obtidos foram os seguintes:

\section{Tabela 16 - Iniciadores por tipo de assunto}

\begin{tabular}{|c|c|c|c|c|}
\hline \multirow[t]{2}{*}{ Assunto } & Marcador & Conectivo & Zero & Repetição \\
\hline & apls. freq. p.rel. & apls. freq. p.rel. & apls. freq. p.rel. & apls. freq. p.rel. \\
\hline Complexo & $592 / 234=925 \% . \mathbf{3 3}$ & $445 / 2349=19 \% .18$ & $1208 / 2349=51 \% \quad .23$ & $104 / 2349=4 \% .27$ \\
\hline Geral & $721 / 4437=16 \% \quad .25$ & $1120 / 4437=29 \% .23$ & $2334 / 4437=48 \% \quad .20$ & $262 / 4437=6 \% \quad .32$ \\
\hline Sem Cont. & $23 / 259=9 \% \quad .17$ & $81 / 259=31 \% .35$ & $146 / 259=54 \% \quad .32$ & $9 / 259=3 \% .17$ \\
\hline
\end{tabular}


Os índices nas tabelas acima confirmaram plenamente as hipóteses para a função de polidez exercida pelos marcadores discursivos ou conversacionais. O que se viu foi, justamente, que esses são iniciadores de turno bem mais freqüentes nas argumentações do que nas respostas informativas menos custosas (Tabela 13). São também mais usados nos pedidos de opinião do que nos demais casos (Tabela 14), nas situações de insistência nas perguntas, que acabam por pressionar o entrevistado (Tabela 15) e, finalmente, nos casos em que os falantes devem responder a perguntas mais complexas em comparação às demais (Tabela 16).

\section{OBSERVAÇÕES FINAIS}

Em primeiro lugar, gostaria de ressaltar mais uma vez a dificuldade em esgotar a lista de possíveis "marcadores" na posição de início de turno. Delimitar se uma expressão perifrástica é ou não um marcador constitui um dos problemas mais importantes para os que estudam este assunto. Cada forma parece ter funções especializadas, cujo estudo detalhado precisará examinar não apenas no início de turno mas também as demais posições no discurso. Sem dúvida é necessário aprofundar o exame em separado de cada partícula. Ao abordar todo o conjunto dos dados, que englobou 43 tipos de marcas, foi possível destacar os problemas na categorização destas formas. A questão de suas funções, num continuum da sintaxe para o discurso e interação (Silva \& Macedo, 1992; Votre \& Vincent, \& Laforet, 1993; Hopper \& Traugott, 1992), foi resolvida de maneira satisfatória com a separação dos marcadores conversacionais dos itens que ainda atuam tanto na sintaxe como no discurso, chamados aqui de "conectivos".

A decisão metodológica de fixar a atenção no início do turno foi importante, pois permitiu examinar a variação de itens em todos os turnos, e, ao mesmo tempo, utilizar a metodologia variacionista de maneira ortodoxa num trabalho sobre a interação discursiva. Além disso, a pesquisa mostrou também a importância do início do turno 
como um local onde a presença de qualquer marca acaba por cumprir uma função pragmática, lado a lado com a sua função sintática. Trata-se, sem dúvida, de uma ilustração patente de uma postura teórica funcionalista, pois defendo que forças externas à estrutura lingüística explicam como itens originários da sintaxe passam a ser usados com funções discursivas por pressões interacionais, num processo que culminará com a sua gramaticalização em novas "categorias". Finalmente, ficou patente mais uma vez a grande aplicabilidade das teorias de polidez aos contextos interacionais aqui destacados, o que cada vez mais nos leva a crer na universalidade do princípios que regem a proposta básica de Brown e Levinson.

\section{NOTAS}

${ }^{1}$ A Amostra "Censo" é constituída por falantes homens e mulheres, de escolaridade entre primeiro e segundo graus, em faixa etária variando de 7 anos a mais de 50 anos de idade, que tenham aprendido sua primeira língua no Município do Rio de Janeiro. Os dados deste trabalho não incluíram a faixa de 7 a 14 anos.

${ }^{2}$ A lista de tipos de iniciadores foi feita com base em 4464 dados.

${ }^{3} \mathrm{O}$ cálculo da Tabela 2 foi feito com base em 4476 dados. Mais 12 turnos foram incluídos.

${ }^{4}$ A Tabela 3 foi calculada com base em 4019 dados, as Tabelas 4 e 5 foram calculadas com base em 3819 dados, sendo a Tabela 6 calculada com base em 3619 dados. Isso ocorreu porque alguns tipos de estruturas acabaram sendo retirados, antes de serem transformados em "demais casos duvidosos" e rodados novamente. Asseguro, porém, que essa pequena diferença não altera as conclusões que extraí dos resultados.

\section{REFERÊNCIAS BIBLIOGRÁFICAS}

BERNARDO, S.P. Formas de polidez das perguntas em entrevistas. Relatório E29/150.148/89 apresentado à FAPERJ. Rio de Janeiro, Faculdade de Letras da UFRJ. mimeo, 1989.

BROWN, P. \& LEVINSON, S. Universals in language usage: Politeness phenomena. In E. Goody, ed., Questions and politeness. Cambridge: Cambridge University Press. p. 56-324, 1978. 
BROWN, P. \& LEVINSON, S. Politeness: Some universals in language use. Cambridge: Cambridge University Press, 1987.

CASTILHO, A. Variedades conversacionais. ABRALIN, Boletim 5, p.40-52, 1983.

GIVON, T. On understanding grammar. N. York: Academic Press, 1979.

HOPPER \& TRAUGOTT. Grammaticalization. Cambridge: Cambridge University Press, 1992.

MACEDO, A. T. Aquisição de marcadores em primeira e em segunda língua. In C. Roncarati \& M.C. Mollica, orgs., Variação e aquisição. Rio de Janeiro: Tempo Brasileiro, p. 117-126, 1997a.

Acquisition and change of discourse markers in first and second language. Comunicação apresentada no 26th NWAVE. Québec, Université Laval. mimeo, $1997 \mathrm{~b}$.

MACEDO, A. \& SILVA, G.M. O papel dos marcadores na interação. São Paulo, II Encontro Nacional da ANPOLL. mimeo, 1989.

MACEDO, A.T. \& BRITO, L.F. As formas de polidez nos pedidos em português. Anais do X Encontro Nacional de Lingüística, Rio de Janeiro, PUC, Departamento de Letras. (congresso realizado em 1985), 1989.

MARCUSCHI, L.A. Análise da Conversação. São Paulo: Ática, 1986.

NICHOLS, J. Functional theories of grammar. In Annual Review of Anthropology. Berkeley: Annual Reviews Inc., 1984.

PINTZUK, S. VARBRUL Program. Philadelphia: University of Pennsylvania. mimeo, 1988.

ROSA, M. Marcadores de atenuação. São Paulo: Contexto, 1992.

ROULET, E. \& alii. L'articulation du discours en français contemporain. Berne: Peter Lang, 1985.

SCHIFFRIN, D. Discourse markers. Cambridge: Cambridge University Press, 1986.

SILVA, G. M., \& MACEDO. Discourse markers in the spoken Portuguese of Rio de Janeiro. Language Variation and Change 4, p. 235-249, 1992.

SILVA, G.M. \& MACEDO, A. Marcadores do discurso na fala no Rio de Janeiro. Anais do XI Encontro Nacional de Lingüística da PUC. Rio de Janeiro, PUC, Dep. Letras, 1988.

Análise sociolingüística de alguns marcadores conversacionais. In A. T. Macedo, C. Roncarati \& M.C. Mollica, orgs., Variação e discurso. Rio de Janeiro: Tempo Brasileiro, p.11- 49, 1996.

SILVA, G. M. O. \& SCHERRE, M.M.P. Padrões sociolingüisticos. Rio de Janeiro: Tempo Brasileiro, 1986. 
VINCENT, D. Les ponctuants de la langue et autres mots du discours. Québec: Nuit Blanche Ed., 1993.

VOTRE, S.,VINCENT, D., \& LAFORET, M. Grammaticalization et degrammaticalization. Québec, Université Laval. mimeo, 1993. 